\title{
Does surgeon experience affect outcomes in pathologic stage I lung cancer?
}

\author{
Paul J. Scheel III, BS, Traves D. Crabtree, MD, Jennifer M. Bell, BSN, Christine Frederiksen, MS, \\ Stephen R. Broderick, MD, A. Sasha Krupnick, MD, Daniel Kreisel, MD, PhD, \\ G. Alexander Patterson, MD, Bryan F. Meyers, MD, MPH, and Varun Puri, MD, MSCI
}

\begin{abstract}
Objective: The study objective was to evaluate the influence of surgeon experience on outcomes in early-stage non-small cell lung cancer.

Methods: In an institutional database, patients undergoing operations for pathologic stage I non-small cell lung cancer were categorized by surgeon experience: within 5 years of completion of training, the low experience group; with 5 to 15 years of experience, the moderate experience group; and with more than 15 years, the high experience group.
\end{abstract}

Results: From 2000 to 2012, 800 operations (638 lobectomies, 162 sublobar resection) were performed with the following distribution: low experience 178 (22.2\%), moderate experience 224 (28.0\%), and high experience 398 (49.8\%). Patients in the groups were similar in age and comorbidities. The use of videoassisted thoracoscopic surgery was higher in the moderate experience group (low experience: 62/178 [34.8\%], moderate experience: 151/224 [67.4\%], and high experience: $133 / 398$ [33.4\%], $P<.001$ ), as was the mean number of mediastinal (N2) lymph node stations sampled (low experience: $2.8 \pm 1.6$, moderate experience: $3.5 \pm 1.7$, high experience: $2.3 \pm 1.4, P<.001)$. The risk of perioperative morbidity was similar across all groups (low experience: 54/178 [30.3\%], moderate experience: 51/224 [22.8\%], and high experience: 115/398 [28.9\%], $P=.163)$. Five-year overall survival in the moderate experience group was $76.9 \%$ compared with $67.5 \%$ in the low experience group $(P<.001)$ and $71.4 \%$ in the high experience group $(P=.006)$. In a Cox proportional hazard model, increasing age, male gender, prior cancer, and R1 resection were associated with an elevated risk of mortality, whereas being operated on by surgeons with moderate experience and having a greater number of mediastinal (N2) lymph node stations sampled were protective.

Conclusions: The experience of the surgeon does not affect perioperative outcomes after resection for pathologic stage I non-small cell lung cancer. At least moderate experience after fellowship is associated with improved long-term survival. (J Thorac Cardiovasc Surg 2015;149:998-1004)

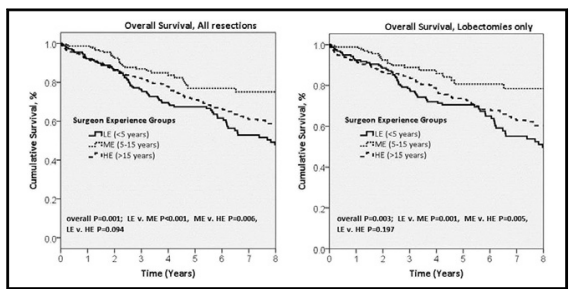

Kaplan-Meier survival curves for all resections of pathologic stage 1 NSCLC.

\section{Central Message}

Moderate surgeon experience is associated with greater use of VATS, higher LN yield, and improved 5-year survival in stage 1 NSCLC.

\section{Perspective}

The impact of surgeon experience on outcomes in stage 1 NSCLC resection remains inadequately studied. We identify surgeon-specific factors associated with improved outcomes, which draws attention to potentially modifiable aspects of patient care. Surgeon training in VATS and adequate LN dissection along with early career supervision provide potential interventions for improved patient care.

See Editorial Commentary page 1005.
From the Division of Cardiothoracic Surgery, Department of Surgery, Washington University School of Medicine, St Louis, Mo.

Grant support to V.P. from the National Institutes of Health K07CA178120, K12CA167540-02 (Paul Calabresi award).

Read at the 40th Annual Meeting of The Western Thoracic Surgical Association, Dana Point, California, June 25-28, 2014.

Received for publication June 25, 2014; revisions received Dec 4, 2014; accepted for publication Dec 15, 2014; available ahead of print Jan 29, 2015.

Address for reprints: Varun Puri, MD, MSCI, 3108 Queeny Tower, Barnes Jewish Hospital, One Barnes Jewish Hospital Plaza, St Louis, MO 63110 (E-mail: puriv@wudosis.wustl.edu).

$0022-5223 / \$ 36.00$

Copyright (c) 2015 by The American Association for Thoracic Surgery

http://dx.doi.org/10.1016/j.jtcvs.2014.12.032
丹 Supplemental material is available online.

Surgical and institutional factors seem to influence morbidity and mortality in resection for esophageal, pancreas, colon, and lung cancers. ${ }^{1-11}$ Several authors have studied surgeon and hospital volumes, and surgeon specialization as possible influential variables, with some reports demonstrating decreased mortality with higher surgical volume and greater degree of surgeon 


\section{Abbreviations and Acronyms \\ $\mathrm{HE}=$ high experience \\ LE $=$ low experience \\ $\mathrm{ME}=$ moderate experience \\ NSCLS $=$ non-small cell lung cancer \\ VATS $=$ video-assisted thoracoscopy}

specialization. ${ }^{6,8,11}$ This is particularly true in surgery for early-stage non-small cell lung cancer (NSCLC). ${ }^{2,10-13}$

However, previous studies evaluating the impact of the individual surgeon on outcomes in lung cancer have focused mainly on thoracic surgical specialization and surgical volume. ${ }^{10-14}$ The role of increasing surgical experience over time as an independent practitioner remains largely unknown. In addition, these studies have largely reported on postoperative mortality, with considerably less attention on perioperative morbidity. ${ }^{4,10,11}$ Because postoperative morbidity is more common than mortality after pulmonary resection $(20 \%$ $40 \%$ vs $1 \%-3 \%),{ }^{12,15}$ the impact of the individual surgeon on early postoperative outcomes remains inadequately understood.

We evaluated the impact of surgeon experience accrued after cardiothoracic surgery fellowship training on the morbidity and mortality of patients undergoing curative resection for pathologic stage I NSCLC. We hypothesized that patients undergoing operations by less-experienced surgeons would demonstrate increased perioperative morbidity and long-term mortality.

\section{PATIENTS AND METHODS}

With institutional review board approval, a single-center, retrospective review of a prospectively maintained lung cancer database was performed. Inclusion criteria were patients who underwent initial resection by lobectomy or sublobar resection for resection of pathologic stage I NSCLC lung cancer and operation performed between January 2000 and December 2012 at Washington University School of Medicine. Only pathologic stage I was included to ensure a uniform population to prevent confounding from upstaging and downstaging. We chose a start date of 2000 for this study because electronic patient records first became available for review at the time. Exclusion criteria included pneumonectomies, operations for recurrent cancer, resections involving multilobes, and operations for subsequent primary cancers in patients who had undergone a prior lung resection (Figure E1).

Surgical experience was determined on the basis of the number of years after the completion of a cardiothoracic surgery fellowship for the operating surgeon at the time of surgery. Operations conducted within the first 5 years of practice after specialty training for the surgeon were classified as the low experience (LE) group; operations performed by surgeons with 5 to 15 years of experience were classified as the moderate experience (ME) group; and operations performed by surgeons with more than 15 years of post-fellowship experience were classified as the high experience (HE) group. Thus, cases performed by a single surgeon could be in different groups depending on when a particular operation was performed in that surgeon's postfellowship career.

We abstracted the details of patient demographics, diagnosis, workup, operation, perioperative course, and outcomes from the institutional database. Missing data were obtained by review of patient charts. Perioperative events were defined per the Society of Thoracic Surgeons datacollection guidelines. ${ }^{16}$ Patient survival was determined from clinic notes and supplemented by querying the Social Security Death Index.

\section{Statistics}

Data were managed with Microsoft Excel (Microsoft Corp, Redmond, Wash) and analyzed using SPSS 21.0 for Windows (SPSS Inc, Chicago, III). Descriptive statistics were expressed as mean \pm standard deviation unless otherwise specified. Categoric data were expressed as counts and percentages. Comparisons between normally distributed continuous variables were performed with 1-way analysis of variance or the $t$ test, and differences among the categoric data were analyzed with the chi-square test. Post hoc analyses for pairwise comparisons were performed using the Bonferroni method for categoric data and the Tukey method for continuous variables. Kaplan-Meier survival plots were generated and groups were compared using the log-rank test. For pairwise comparisons using the Bonferroni method, a $P$ value less than .017 was considered significant. A Cox proportional hazard model was then fitted to determine variables that affected the risk of long-term mortality. For this model, we considered age, gender, smoking status, coronary artery disease, hypertension, forced expiratory volume in 1 second percent, diffusing capacity of carbon monoxide percent, body mass index, prior cancer, surgeon experience, procedure (lobectomy vs sublobar resection), adequacy of resection (negative margins), number of mediastinal (N2) lymph node stations sampled, and type of incision (video-assisted thoracoscopy [VATS] vs thoracotomy) as independent variables.

After an initial exploratory analysis of all patients with pathologic stage I lung cancer who underwent resection, we dichotomized patients into a lobectomy group and a sublobar resection group. Identical analyses as described earlier were performed in these groups. We also performed a subgroup analysis to determine whether there was an impact of accrued experience for each individual surgeon.

For those surgeons who began performing operations during the study period, their first 25 operations were compared with their subsequent 25 operations with a comparison of both preoperative variables and outcomes.

\section{RESULTS}

Between January 2000 and December 2012, 800 patients underwent resection for pathologic stage I lung cancer by 8 surgeons. Of these operations, 178 resections $(22.2 \%)$ were in the LE group $(<5$ years experience for the operating surgeon), 224 resections $(28.0 \%)$ were in the ME group (5$\leq 15$ years experience for the surgeon), and 398 resections $(49.8 \%)$ were in the HE group (15 years experience for the surgeon). Operations were performed by 6 different surgeons in the LE group, 5 surgeons in the ME group, and 2 surgeons in the HE group. Patients in the 3 groups were similar in age and distribution of comorbidities (Table 1). The LE group had a higher proportion of male patients and nonwhite patients than the HE group (Table 1).

Of the 800 operations, there were 638 lobectomies $(79.8 \%)$ and 162 sublobar resections $(20.2 \%)$. The LE group was more likely to undergo lobectomies than sublobar resections (157/178 [88.2\%]) compared with the ME group $(176 / 224$ [78.6\%], $P=.011)$ and HE group (305/ $398[76.6 \%], P=.001)$. The use of VATS was higher in the ME group than in the other 2 groups (LE: 62/178 [34.8\%], ME: 151/224 [67.4\%], HE: 133/398 [33.4\%], 
TABLE 1. Patient demographics and comorbidities for all resections (lobectomy and sublobar resection)

\begin{tabular}{|c|c|c|c|c|}
\hline Variable & $\mathbf{L E}(n=178)$ & $\operatorname{ME}(n=224)$ & HE $(n=398)$ & $\boldsymbol{P}$ \\
\hline Mean age (y) & $64.6 \pm 11.4$ & $64.3 \pm 10.5$ & $65.5 \pm 11.4$ & .365 \\
\hline Male gender & $95(53.4 \%)$ & $104(46.4 \%)$ & $162(44.9 \%)$ & $.017 *$ \\
\hline Nonwhite race & $38(21.3 \%)$ & $30(13.4 \%)$ & $42(10.6 \%)$ & $.002 \dagger$ \\
\hline Smoking status & & & & .144 \\
\hline Never & $14(7.9 \%)$ & $30(13.4 \%)$ & $52(13.1 \%)$ & \\
\hline Past & $91(51.1 \%)$ & $112(50.0 \%)$ & $218(54.8 \%)$ & \\
\hline Current & $73(41.0 \%)$ & $82(36.6 \%)$ & $128(32.2 \%)$ & \\
\hline Prior stroke & $11(6.2 \%)$ & $12(5.4 \%)$ & $27(6.8 \%)$ & .779 \\
\hline Coronary artery disease & $40(22.5 \%)$ & $34(15.2 \%)$ & $81(20.4 \%)$ & .145 \\
\hline Hypertension & $103(57.9 \%)$ & $120(53.6 \%)$ & $216(54.3 \%)$ & .652 \\
\hline Congestive heart failure & $3(1.7 \%)$ & $2(0.9 \%)$ & $8(2.0 \%)$ & .570 \\
\hline Peripheral vascular disease & $10(5.6 \%)$ & $7(3.1 \%)$ & $18(4.5 \%)$ & .469 \\
\hline Baseline FEV1\% predicted & $79.7 \pm 21.1$ & $80.9 \pm 19.9$ & $79.3 \pm 22.1$ & .656 \\
\hline Baseline DLCO $\%$ predicted & $70.8 \pm 21.6$ & $72.7 \pm 20.6$ & $71.4 \pm 21.6$ & .642 \\
\hline Body mass index & $27.1 \pm 5.8$ & $27.2 \pm 5.9$ & $26.9 \pm 6.2$ & .827 \\
\hline Prior cancer & $69(38.8 \%)$ & $77(34.4 \%)$ & $134(33.7 \%)$ & .483 \\
\hline Clinical stage & & & & .666 \\
\hline I & $159(89.3 \%)$ & $207(92.4 \%)$ & $368(92.5 \%)$ & \\
\hline II & $9(5.1 \%)$ & $7(3.1 \%)$ & $16(4.0 \%)$ & \\
\hline III & $10(5.6 \%)$ & $10(4.5 \%)$ & $14(3.5 \%)$ & \\
\hline
\end{tabular}

$D L C O$, Carbon dioxide diffusing capacity; $F E V I$, forced expiratory volume in 1 second; $H E$, high experience; $L E$, low experience; $M E$, moderate experience. *LE versus ME, $P=.167$, LE versus HE, $P=.005$, ME versus HE, $P=.166$. $\nmid$ LE versus ME, $P=.047$, LE versus HE, $P=.001$, ME versus HE, $P=.222$.

all $P<.001$ ). Because VATS was more widely adopted in our program in 2007 and 2008, we performed a subgroup analysis considering operations performed after January 2008. The ME group was still more likely to undergo VATS operations $(133 / 160[83.1 \%])$ compared with the LE group $(49 / 79$ [62.0\%], $P<.001)$ but was similar to the HE group (129/177 [72.9\%], $P=.024$, not significant with Bonferroni correction). The number of microscopically incomplete resections (R1 resections) was similar across all groups (LE: 5/178 [2.8\%], ME: 7/224 [3.1\%], HE: $10 / 398[2.5 \%], P=.903)$. The mean number of mediastinal (N2) lymph node stations sampled per operation was highest for the ME group and lowest for the HE group
(LE: $2.8 \pm 1.6$, ME: $3.5 \pm 1.7$, HE: $2.3 \pm 1.4, P<.001$, LE vs ME, $P<.001$, LE vs HE, $P=.001$, ME vs HE, $P<.001)$.

The risk of any perioperative morbidity defined per Society of Thoracic Surgeons criteria was similar across all groups (LE: 54/178 [30.3\%], ME: 51/224 [22.8\%], HE: $115 / 398$ [28.9\%], $P=.163$ ). The risk of specific complications was also similar across the groups (Table 2). There were no differences in length of hospital stay or perioperative mortality among the groups. Unadjusted 5-year overall survival in the ME group was $76.9 \%$ compared with $67.5 \%$ in the LE group $(P<.001)$ and $71.4 \%$ in the HE group $(P=.006)$ (Figure 1, A).

TABLE 2. Comparison of perioperative outcomes among the 3 groups for all resections (lobectomy and sublobar resection)

\begin{tabular}{|c|c|c|c|c|}
\hline Variable & $\mathbf{L E}(\mathbf{n}=\mathbf{1 7 8})$ & $\operatorname{ME}(n=224)$ & HE $(n=398)$ & $P$ value \\
\hline Prolonged air leak & $13(7.3 \%)$ & $8(3.6 \%)$ & $33(8.3 \%)$ & .075 \\
\hline Pneumonia & $11(6.2 \%)$ & $10(4.5 \%)$ & $21(5.3 \%)$ & .745 \\
\hline Bronchopleural fistula & $0(0.0 \%)$ & $1(0.4 \%)$ & $2(0.5 \%)$ & .646 \\
\hline Blood transfusion & $4(2.2 \%)$ & $1(0.4 \%)$ & $4(1.0 \%)$ & .224 \\
\hline Empyema & $2(1.1 \%)$ & $1(0.4 \%)$ & $0(0.0 \%)$ & .123 \\
\hline Respiratory failure & $11(6.2 \%)$ & $7(3.1 \%)$ & $25(6.3 \%)$ & .212 \\
\hline Dysrhythmia & $24(13.5 \%)$ & $24(10.7 \%)$ & $50(12.6 \%)$ & .677 \\
\hline Deep vein thrombosis & $4(2.2 \%)$ & $3(1.3 \%)$ & $5(1.3 \%)$ & .647 \\
\hline Renal failure & $2(1.1 \%)$ & $1(0.4 \%)$ & $4(1.0 \%)$ & .712 \\
\hline Hemorrhage requiring reoperation & $2(1.1 \%)$ & $0(0.0 \%)$ & $4(1.0 \%)$ & .305 \\
\hline Stroke & $0(0.0 \%)$ & $2(0.9 \%)$ & $2(0.5 \%)$ & .452 \\
\hline Any perioperative morbidity & $54(30.3 \%)$ & $51(22.8 \%)$ & $115(28.9 \%)$ & .163 \\
\hline Mean length of hospital stay & $6.6 \pm 6.3$ & $5.3 \pm 4.8$ & $5.8 \pm 6.6$ & .086 \\
\hline Readmission within $30 \mathrm{~d}$ & $13(7.3 \%)$ & $11(4.9 \%)$ & $32(8.0 \%)$ & .335 \\
\hline $30 \mathrm{~d} /$ hospital mortality & $2(1.1 \%)$ & $0(0.0 \%)$ & $6(1.5 \%)$ & .190 \\
\hline
\end{tabular}

$H E$, High experience; $L E$, low experience; $M E$, moderate experience. 
A

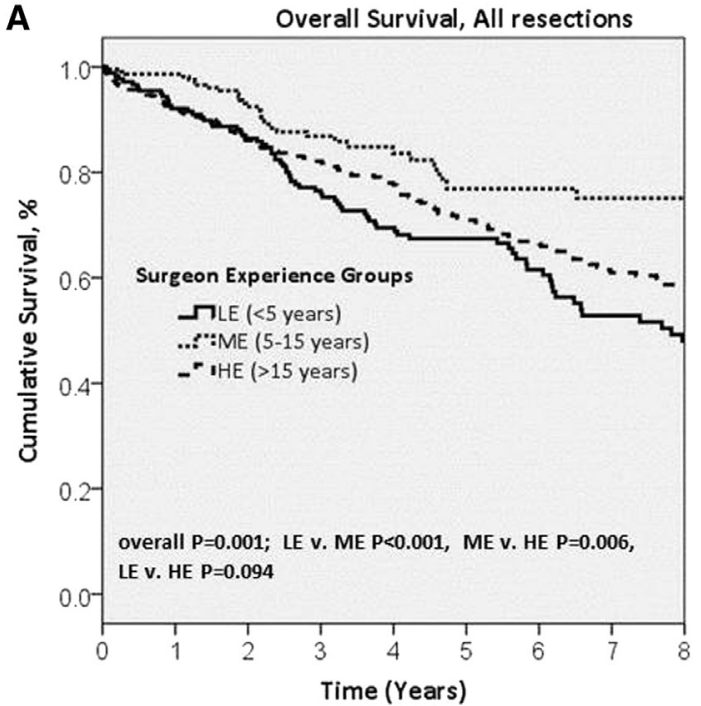

\begin{tabular}{|c|c|c|c|}
\hline Time & No. at risk, LE & No. at risk, ME & No. at risk, HE \\
\hline 1 year & 164 & 198 & 350 \\
\hline 2 years & 152 & 149 & 301 \\
\hline 3 years & 125 & 102 & 258 \\
\hline 4 years & 105 & 68 & 211 \\
\hline 5 years & 86 & 53 & 170 \\
\hline
\end{tabular}

B

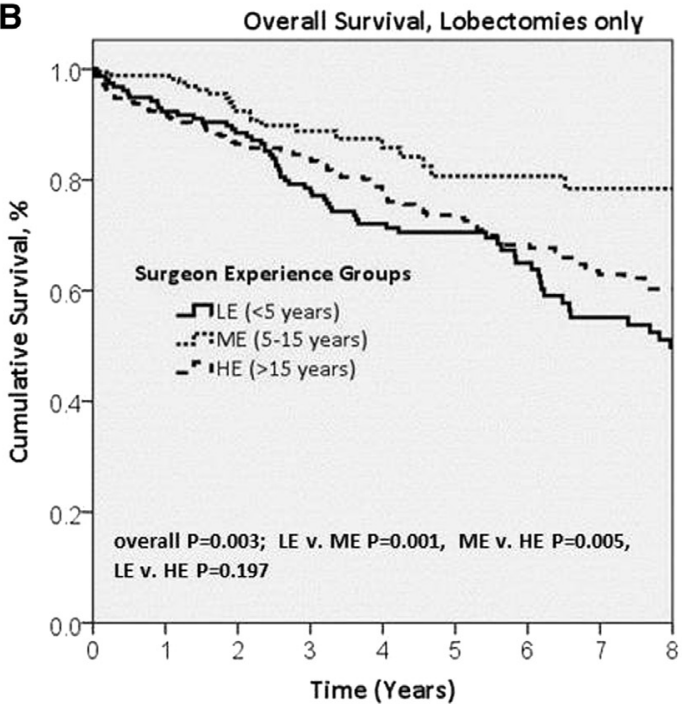

\begin{tabular}{|c|c|c|c|}
\hline Time & No. at risk, LE & No. at risk, ME & No. at risk, HE \\
\hline 1 year & 145 & 158 & 270 \\
\hline 2 years & 137 & 118 & 238 \\
\hline 3 years & 114 & 82 & 214 \\
\hline 4 years & 97 & 54 & 176 \\
\hline 5 years & 79 & 43 & 145 \\
\hline
\end{tabular}

FIGURE 1. A, Kaplan-Meier overall survival for all resections (lobectomy and sublobar). B, Kaplan-Meier overall survival for patients undergoing lobectomy only. $H E$, High experience; $L E$, low experience; $M E$, moderate experience.

During the study period, 638 patients underwent lobectomy for pathologic stage I lung cancer. Of these, 157 $(24.6 \%)$ were in the LE group, $176(27.6 \%)$ were in the ME group, and 305 (47.8\%) were in the HE group. Again, the LE group comprised a higher proportion of male patients and nonwhite patients than the HE group but not the ME group (Table E1). By considering operations performed from January 2008 onward (since the more widespread use of VATS), the ME and HE groups were more likely to undergo operations via VATS compared with the LE group (LE 40/67 [59.7\%], ME 103/126 [81.7\%], HE 87/123 [70.7\%], overall $P<.001 ; \mathrm{LE}$ vs ME, $P=.001 ; \mathrm{ME}$ vs HE, $P=.041$; LE vs HE, $P=.123$ ). The proportion of R1 resections was similar across the 3 groups (LE: 3/157 [1.9\%], ME: 6/176 [3.4\%], HE: 5/305 [1.6\%], $P=.426)$. The number of mediastinal (N2) lymph node stations

TABLE 3. Comparison of perioperative outcomes for patients undergoing lobectomy

\begin{tabular}{|c|c|c|c|c|}
\hline Variable & LE $(n=157)$ & $\operatorname{ME}(n=176)$ & HE $(n=305)$ & $P$ value \\
\hline Air leak & $12(7.6 \%)$ & $5(2.8 \%)$ & $26(8.5 \%)$ & $.050^{*}$ \\
\hline Pneumonia & $10(6.4 \%)$ & $9(5.1 \%)$ & $18(5.9 \%)$ & .882 \\
\hline Bronchopleural fistula & $0(0.0 \%)$ & $1(0.6 \%)$ & $2(0.7 \%)$ & .606 \\
\hline Blood transfusion & $4(2.5 \%)$ & $1(0.6 \%)$ & $4(1.3 \%)$ & .304 \\
\hline Empyema & $2(1.3 \%)$ & $1(0.6 \%)$ & $0(0.0 \%)$ & .162 \\
\hline Respiratory failure & $11(7.0 \%)$ & $6(3.4 \%)$ & $23(7.5 \%)$ & .180 \\
\hline Dysrhythmia & $23(14.6 \%)$ & $24(13.6 \%)$ & $44(14.4 \%)$ & .960 \\
\hline Deep vein thrombosis & $4(2.5 \%)$ & $3(1.7 \%)$ & $2(0.7 \%)$ & .244 \\
\hline Renal failure & $2(1.3 \%)$ & $1(0.6 \%)$ & $3(1.0 \%)$ & .796 \\
\hline Hemorrhage requiring reoperation & $2(1.3 \%)$ & $0(0.0 \%)$ & $3(1.0 \%)$ & .362 \\
\hline Stroke & $0(0.0 \%)$ & $1(0.6 \%)$ & $1(0.3 \%)$ & .650 \\
\hline Any perioperative morbidity & $50(31.8 \%)$ & $46(26.1 \%)$ & $92(30.2 \%)$ & .487 \\
\hline Mean length of hospital stay & $6.96 \pm 6.63$ & $5.55 \pm 4.34$ & $6.24 \pm 7.15$ & .128 \\
\hline Readmission within $30 \mathrm{~d}$ & $13(8.3 \%)$ & $10(5.7 \%)$ & $26(8.5 \%)$ & .502 \\
\hline $30 \mathrm{~d} /$ hospital mortality & $2(1.3 \%)$ & $0(0.0 \%)$ & $5(1.6 \%)$ & 244 \\
\hline
\end{tabular}

$H E$, High experience; $L E$, low experience; $M E$, moderate experience. * $\mathrm{LE}$ versus $\mathrm{ME}, P=.047$ (statistically not significant after adjustment for subgroup analysis); $\mathrm{LE}$ versus $\mathrm{HE}$ $P=.744 ;$ ME versus HE, $P=.014$ (statistically significant). 
TABLE 4. Cox proportional hazard model for overall survival in entire cohort of patients undergoing lobectomy or sublobar resection

\begin{tabular}{|c|c|c|}
\hline Variable & HR & $\mathbf{9 5} \% \mathbf{C I}$ \\
\hline \multicolumn{3}{|l|}{ Surgeon experience included } \\
\hline Age & 1.05 & $1.03-1.06$ \\
\hline Gender (male) & 1.48 & $1.13-1.94$ \\
\hline Race (nonwhite) & 1.24 & $0.87-1.77$ \\
\hline Smoking status (never) & Reference category & \\
\hline Smoking (past) & 0.93 & $0.56-1.55$ \\
\hline Smoking (current) & 1.36 & $0.80-2.31$ \\
\hline Coronary artery disease & 1.20 & $0.89-1.61$ \\
\hline Hypertension & 1.13 & $0.86-1.48$ \\
\hline Baseline FEV $1 \%$ predicted (scaled) & 0.87 & $0.72-1.05$ \\
\hline Baseline DLCO \% predicted (scaled) & 0.88 & $0.75-1.02$ \\
\hline Body mass index & 0.98 & $0.95-1.01$ \\
\hline Prior cancer & 1.33 & $1.02-1.72$ \\
\hline Experience $(<5$ y) & Reference category & \\
\hline Experience (5-15 y) & 0.52 & $0.34-0.80$ \\
\hline Experience $(>15 \mathrm{y})$ & 0.77 & $0.58-1.03$ \\
\hline Sublobar resection & 0.98 & $0.70-1.38$ \\
\hline Thoracoscopic approach & 0.89 & $0.64-1.22$ \\
\hline $\begin{array}{l}\text { No. of mediastinal (N2) lymph node } \\
\text { stations sampled }\end{array}$ & 0.90 & $0.82-0.98$ \\
\hline $\mathrm{R} 1$ resection & 2.55 & $1.28-5.10$ \\
\hline \multicolumn{3}{|l|}{ Surgeon experience not included } \\
\hline Age & 1.05 & $1.03-1.06$ \\
\hline Gender (male) & 1.48 & $1.13-1.94$ \\
\hline Race (nonwhite) & 1.30 & $0.912-1.86$ \\
\hline Smoking status (never) & Reference category & \\
\hline Smoking (past) & 0.97 & $0.58-1.61$ \\
\hline Smoking (current) & 1.39 & $0.82-2.36$ \\
\hline Coronary artery disease & 1.20 & $0.89-1.62$ \\
\hline Hypertension & 1.11 & $0.85-1.46$ \\
\hline Baseline FEV $1 \%$ predicted scaled & 0.88 & $0.73-1.06$ \\
\hline Baseline DLCO $\%$ predicted scaled & 0.86 & $0.74-1.01$ \\
\hline Body mass index & 0.98 & $0.95-1.01$ \\
\hline Prior cancer & 1.33 & $1.02-1.72$ \\
\hline Sublobar resection & 0.93 & $0.67-1.31$ \\
\hline Thoracoscopic approach & 0.83 & $0.60-1.14$ \\
\hline $\begin{array}{l}\text { No. of mediastinal (N2) lymph node } \\
\text { stations sampled }\end{array}$ & 0.89 & $0.82-0.97$ \\
\hline $\mathrm{R} 1$ resection & 2.57 & $1.29-5.12$ \\
\hline
\end{tabular}

FEV $1 \%$ and DLCO $\%$ were scaled to the interquartile range. The $\mathrm{HR}$ for $\mathrm{FEV} 1 \%$ and DLCO \% represents the hazard of the event occurring for a typical person in the middle of the upper half of the distribution compared with the hazard of the event for a typical person in the middle of the lower half of the distribution. $C I$, Confidence interval; $D L C O$, carbon dioxide diffusing capacity; $F E V I$, forced expiratory volume in 1 second; $H R$, hazard ratio.

sampled was again highest in the ME group and lowest in the HE group (LE: $3.0 \pm 1.5$, ME: $3.8 \pm 1.5$, HE: $2.5 \pm 1.5$, overall $P<.001 ;$ LE vs ME, $P<.001 ;$ LE vs HE, $P=.001 ;$ ME vs HE, $P<.001)$. Patients in the ME group had a lower incidence of prolonged postoperative air leak, whereas the remaining perioperative outcomes were similar across the groups (Table 3). Five-year overall survival in the ME group was $80.7 \%$ compared with $70.5 \%$ in the LE group $(P<.001)$ and $73.6 \%$ in the HE group $(P=.006)$ (Figure $1, B)$. In comparing data on each individual surgeon's initial 25 and next 25 cases, no clear trends were seen.

In the Cox proportional hazard model evaluating the entire cohort (lobectomy and sublobar resections), increasing age, male gender, prior cancer, and R1 resection were associated with an elevated risk of mortality. Being in the ME group and having a greater number of mediastinal (N2) lymph node stations sampled were associated with a lower hazard of long-term mortality (Table 4). In a subgroup analysis, identical results were observed for patients undergoing lobectomy (data not shown).

\section{DISCUSSION}

Our main findings in this study are that experience after fellowship training does not affect short-term outcomes after resection for lung cancer. However, surgeons with at least moderate experience have a higher use of minimally invasive techniques and possibly improved long-term survival.

Currently, most statistical models use a variety of patientand disease-specific variables, such as age, pulmonary function, comorbidity scores, and pathologic stage, to predict short- and long-term outcomes after pulmonary resection. ${ }^{16-20}$ In addition, a number of studies have explored the role of surgeon specialty training, hospital case volume, and surgeon case volume in perioperative morbidity and longterm survival after surgery for lung cancer, but the results have been inconsistent. ${ }^{2,4-10-14}$ These studies have largely used administrative databases and pooled information from multiple centers to conduct the analyses. This strategy, although providing a robust sample size in most cases, cannot account for variations in practice patterns across surgeons and institutions, in both the intraoperative and the postoperative care of patients. Thus, we explored the impact of the individual surgeon's experience as a possible determinant of outcomes in a setting where all the surgeons are specialty trained, have been trained in the same setting, and use uniform perioperative management protocols.

In one of the first studies of its kind in lung cancer, Bach and colleagues ${ }^{13}$ evaluated the volume of lung resections at individual centers and found an inverse relationship between volume and postoperative complications. They also noted improved long-term survival at higher-volume hospitals. Subsequently, Goodney and colleagues ${ }^{2}$ analyzed the national Medicare database and noted that perioperative mortality was lower for specialty-trained thoracic surgeons compared with others after adjusting for hospital volumes. They considered more than 20 cases per year to indicate a high-volume surgeon. By these criteria, all the operators involved in our study are specialty trained in thoracic surgery and are highvolume surgeons. Other authors, including those from Europe and Asia, have also investigated the volume-outcomes relationship with mixed results. Sioris and colleagues ${ }^{10}$ noted no effect of hospital volume on outcomes, but university hospitals performed better than community hospitals. ${ }^{10}$ Lien and 
colleagues ${ }^{4}$ studied a population from Taiwan and reported lower in-hospital mortality with increasing individual surgeon volume of resections. Reviews have raised questions about the methodologic quality of studies in the field, and Kozower and Stukenborg ${ }^{14}$ thought that " careful examination of the literature demonstrates that lung cancer resection volume is not strongly associated with mortality and should not be used as a proxy measure for quality." Finally, in a metaanalysis, von Meyenfeldt and colleagues ${ }^{11}$ pooled data from 19 studies and concluded that although hospital volume and surgeon specialty are determinants of outcome, individual surgeon volume is not important.

Our study focused on measuring the impact of the experience of a surgeon measured in number of years in practice after completing cardiothoracic surgical fellowship training. Although this approach is novel to lung cancer surgery, it has been used in evaluating other cancer operations. ${ }^{3,21}$ It has been shown that despite existing evidencebased guidelines, decision-making in surgery continues to be strongly affected by anecdotal experience. ${ }^{22}$

We did not find a significant difference in perioperative morbidity or mortality with varying surgeon experience. Except for relatively minor differences in demographics, the patients across the 3 groups were similar in comorbidity. All except 1 surgeon in the group have been trained by the senior-most surgeon in this cohort and have fairly similar patterns of practice in both patient selection and operative procedures. These factors can likely explain the consistent perioperative outcomes across groups. Previous studies evaluating perioperative outcomes have largely focused on mortality, ${ }^{2,4,11}$ and those studying postoperative morbidity and the surgical volume have not evaluated the individual surgeon's impact on outcomes. ${ }^{13}$

Adequate lymph node sampling/dissection is one of the cornerstones in lung cancer surgery. Others have demonstrated improved patient outcomes in node-negative NSCLC with greater number of lymph nodes sampled. ${ }^{23-25}$ Our use of the number of lymph node stations sampled was driven by the data available to us in our database and has been recognized by other authors as a surrogate for the number of lymph nodes resected. ${ }^{25}$ We noted that the ME group tended to have a higher yield of lymph nodes, and this also correlated with survival. It is plausible that surgeons who are in the early phase of their careers may be completely focused on "getting the specimen out" with less attention being paid to nodal sampling with its added operative time and perceived additional morbidity. Highly experienced surgeons may have a lower lymph node yield because the importance of nodal sampling has been predominantly realized over the last 2 decades, and these surgeons may have completed training in an earlier time period. It is also plausible that there may be a higher degree of trainee involvement with highly experienced surgeons, and some parts of the operation (including lymph node assessment) may be performed independently by the residents.
Regardless, our finding points to the need for continued attention toward highlighting the importance of adequate nodal assessment.

We noted that patients operated on by moderately experienced surgeons had a somewhat longer overall survival compared with the other 2 groups. This correlated with better mediastinal lymph node assessment by the moderately experienced surgeons, a factor that has been associated with improved survival in previous publications. ${ }^{23-25}$ Also, there was a higher likelihood for the use of VATS techniques in the ME group. Others have reported improved long-term survival after VATS lobectomy (compared with open thoracotomy) in systematic reviews and meta-analyses of studies involving patients with clinical stage I NSCLC. ${ }^{26,27}$ The other variables noted to be associated with diminished survival, namely, increasing age, male gender, and incomplete resection, are well-established predictors for poorer long-term survival in lung cancer. ${ }^{16,18}$

\section{Study Limitations}

The study's retrospective nature introduces the possibility of selection bias. With patients from a single center, a limited sample size may lead to type II error where true differences between groups may be missed. We had 8 surgeons in the group, largely similarly trained; thus, it may limit the generalizability of our findings. Last, intraoperative decision-making is subjective and perioperative management varies, which could lead to misclassification bias. To limit such misclassification, we used Society of Thoracic Surgeons guidelines for classifying perioperative adverse events, and when in doubt on chart review, an event was classified as positive.

\section{CONCLUSIONS}

Our study demonstrated that surgeon experience does not affect early perioperative outcomes after resection for earlystage lung cancer. However, patients operated on by moderately experienced surgeons may have better long-term survival after resection for pathologic stage I lung cancer. Expanding this study to a larger patient and surgeon population would be needed to validate the results and identify the underlying causes for these differences to provide the best patient care.

\section{Conflict of Interest Statement}

Traves D. Crabtree reports consulting fees from Ethicon Endosurgery. Bryan F. Meyers reports consulting fees, lecture fees, and grant support from Ethicon Endosurgery. All other authors have nothing to disclose with regard to commercial support.

\section{References}

1. Bilimoria KY, Phillips JD, Rock CE, Hayman A, Prystowsky JB, Bentrem DJ. Effect of surgeon training, specialization, and experience on outcomes for cancer surgery: a systematic review of the literature. Ann Surg Oncol. 2009;16:1799-808. 2. Goodney PP, Lucas FL, Stukel TA, Birkmeyer JD. Surgeon specialty and operative mortality with lung resection. Ann Surg. 2005;241:179-84. 
3. Holm T, Johansson H, Cedermark B, Ekelund G, Rutqvist LE. Influence of hospital- and surgeon-related factors on outcome after treatment of rectal cancer with or without preoperative radiotherapy. Br J Surg. 1997;84:657-63.

4. Lien YC, Huang MT, Lin HC. Association between surgeon and hospital volume and in-hospital fatalities after lung cancer resections: the experience of an Asian country. Ann Thorac Surg. 2007;83:1837-43.

5. McArdle CS, Hole DJ. Influence of volume and specialization on survival following surgery for colorectal cancer. Br J Surg. 2004;91:610-7.

6. Migliore M, Choong CK, Lim E, Goldsmith KA, Ritchie A, Wells FC. A surgeon's case volume of oesophagectomy for cancer strongly influences the operative mortality rate. Eur J Cardiothorac Surg. 2007;32:375-80.

7. Pecorelli N, Balzano G, Capretti G, Zerbi A, Di Carlo V, Braga M. Effect of surgeon volume on outcome following pancreaticoduodenectomy in a high-volume hospital. J Gastrointest Surg. 2012;16:518-23.

8. Porter GA, Soskolne CL, Yakimets WW, Newman SC. Surgeon-related factors and outcome in rectal cancer. Ann Surg. 1998;227:157-67.

9. Prystowsky JB. Are young surgeons competent to perform alimentary tract surgery? Arch Surg. 2005;140:495-502.

10. Sioris T, Sihvo E, Sankila R, Salo J. Effect of surgical volume and hospital type on outcome in non-small cell lung cancer surgery: a Finnish population-based study. Lung Cancer. 2008;59:119-25.

11. von Meyenfeldt EM, Gooiker GA, van Gijn W, Post PN, van de Velde CJ, Tollenaar RA, et al. The relationship between volume or surgeon specialty and outcome in the surgical treatment of lung cancer: a systematic review and meta-analysis. J Thorac Oncol. 2012;7:1170-8.

12. Park HS, Detterbeck FC, Boffa DJ, Kim AW. Impact of hospital volume of thoracoscopic lobectomy on primary lung cancer outcomes. Ann Thorac Surg. 2012;93:372-9.

13. Bach PB, Cramer LD, Schrag D, Downey RJ, Gelfand SE, Begg CB. The influence of hospital volume on survival after resection for lung cancer. $N$ Engl J Med. 2001;345:181-8.

14. Kozower BD, Stukenborg GJ. Lung cancer resection volume: is procedure volume really an indicator of quality? Semin Thorac Cardiovasc Surg. 2012;24:93-8.

15. Puri V, Meyers BF. Video-assisted thoracoscopic surgery lobectomy for lung cancer. Surg Oncol Clin N Am. 2013;22:27-38.

16. Kozower BD, Sheng S, O'Brien SM, Liptay MJ, Lau CL, Jones DR, et al. STS database risk models: predictors of mortality and major morbidity for lung cancer resection. Ann Thorac Surg. 2010;90:875-83.
17. Wright CD, Gaissert HA, Grab JD, O'Brien SM, Peterson ED, Allen MS. Predic tors of prolonged length of stay after lobectomy for lung cancer: a Society of Thoracic Surgeons General Thoracic Surgery Database risk-adjustment model. Ann Thorac Surg. 2008;85:1857-65.

18. Ferguson MK, Siddique J, Karrison T. Modeling major lung resection outcomes using classification trees and multiple imputation techniques. Eur J Cardiothorac Surg. 2008;34:1085-9.

19. Ferguson MK, Gaissert HA, Grab JD, Sheng S. Pulmonary complications after lung resection in the absence of chronic obstructive pulmonary disease: the predictive role of diffusing capacity. J Thorac Cardiovasc Surg. 2009;138:1297-302.

20. Liptay MJ, Basu S, Hoaglin MC, Freedman N, Faber LP, Warren WH, et al. Diffusion lung capacity for carbon monoxide (DLCO) is an independent prognostic factor for long-term survival after curative lung resection for cancer. $J$ Surg Oncol. 2009;100:703-7.

21. Prystowsky JB, Bordage G, Feinglass JM. Patient outcomes for segmental colon resection according to surgeon's training, certification, and experience. Surgery. 2002;132:663-72.

22. Melis M, Karl RC, Wong SL, Brennan MF, Matthews JB, Roggin KK. Evidencebased surgical practice in academic medical centers: consistently anecdotal? J Gastrointest Surg. 2010;14:904-9.

23. Ludwig MS, Goodman M, Miller DL, Johnstone PA. Postoperative survival and the number of lymph nodes sampled during resection of node-negative non-small cell lung cancer. Chest. 2005;128:1545-50.

24. Varlotto JM, Recht A, Nikolov M, Flickinger JC, Decamp MM. Extent of lymphadenectomy and outcome for patients with stage I nonsmall cell lung cancer. Cancer. 2009;115:851-8.

25. Osarogiagbon RU, Ogbata O, Yu X. Number of lymph nodes associated with maximal reduction of long-term mortality risk in pathologic node-negative non-small cell lung cancer. Ann Thorac Surg. 2014;97:385-93.

26. Whitson BA, Groth SS, Duval SJ, Swanson SJ, Maddaus MA. Surgery for earlystage non-small cell lung cancer: a systematic review of the video-assisted thoracoscopic surgery versus thoracotomy approaches to lobectomy. Ann Thorac Surg. 2008;86:2008-18.

27. Chen FF, Zhang D, Wang YL, Xiong B. Video-assisted thoracoscopic surgery lobectomy versus open lobectomy in patients with clinical stage nonsmall cell lung cancer: a meta-analysis. Eur J Surg Oncol. 2013;39: 957-63.

Readers who found these articles interesting may also like to read the following papers found in recent and future issues of our sister publications, Seminars in Thoracic and Cardiovascular Surgery and Operative Techniques in Thoracic and Cardiovascular Surgery!

Current Readings: David Zeltsman. Redefining Minimally Invasive Uniportal Video-Assisted Thoracic Surgery. Semin Thorac Cardiovasc Surg. Autumn 2014;26(3):249-254.

Current Readings: Sumeet Mittal. Failed Hiatus Hernia Repair. Semin Thorac Cardiovasc Surg. Expected publication April 2015.

State of the Art: Frank Detterbeck. The ITMIG Thymic Initiative: A State of the Art for the Study of Thymic Malignancies. Semin Thorac Cardiovasc Surg. Expected publication April 2015.

State of the Art: Richard Freeman. The Theory, Practice and Future of Process Improvement in General Thoracic Surgery. Semin Thorac Cardiovasc Surg. Expected publication April 2015.

State of the Art: Eric Grogan. Using Clinical Risk Models for Lung Nodule Classification. Semin Thorac Cardiovasc Surg. Expected Publication August 2015.

Original Submission: Thomas Watson. Eliminating a need for esophagectomy: endoscopic treatment of Barrett's Esophagus with early esophageal neoplasia. Expected publication April 2015.

Editorial Commentary: Anthony Kim. Endoscopically closing doors. Semin Thorac Cardiovasc Surg. Expected publication April 2015.

Original Submission: Daniela Molena. Incidence and risk factors for respiratory complications in patients undergoing esophagectomy for malignancy: a NSQIP analysis. Semin Thorac Cardiovasc Surg. Expected publication April 2015.

Editorial Commentary: R. Taylor Ripley. Esophageal complications: What are the real results? Semin Thorac Cardiovasc Surg. Expected publication April 2015. 


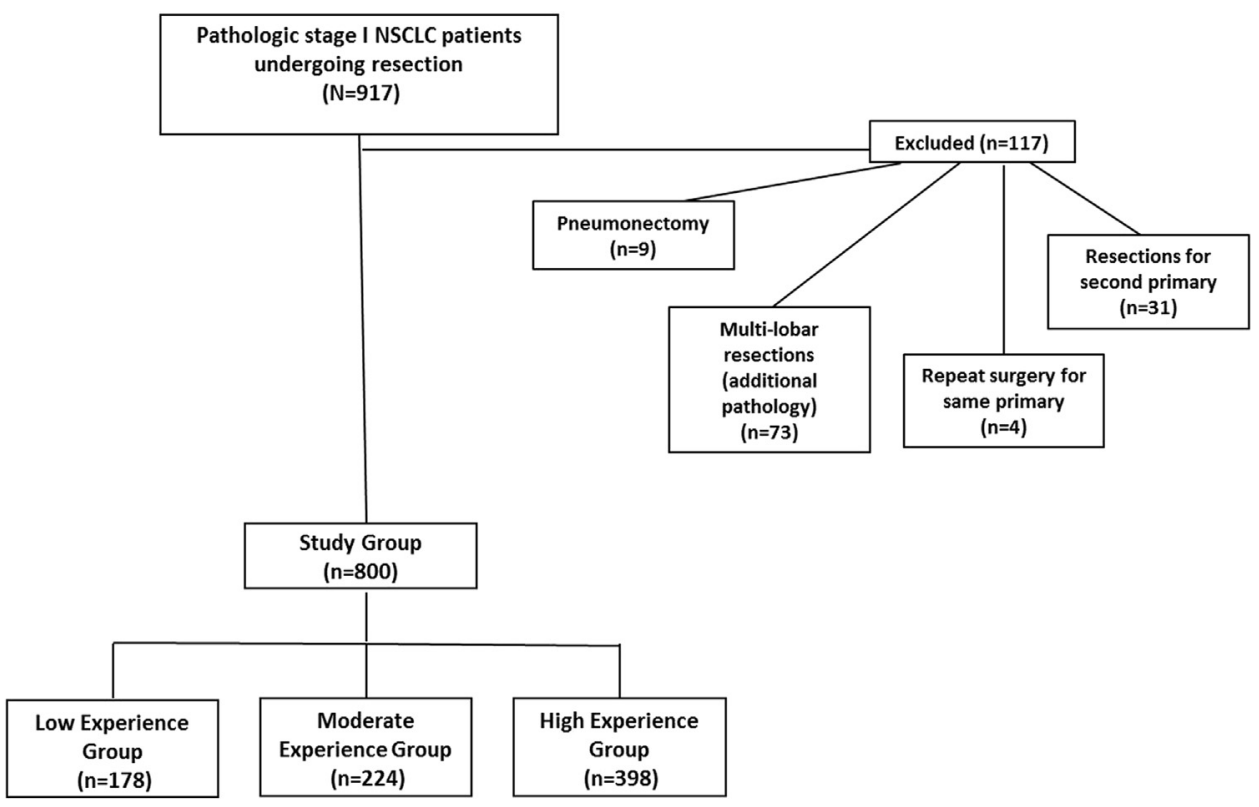

FIGURE E1. CONSORT diagram. NSCLC, Non-small cell lung cancer.

TABLE E1. Patient demographics and comorbidities for patients undergoing lobectomy

\begin{tabular}{|c|c|c|c|c|}
\hline Variable & $\mathbf{L E}(\mathbf{n}=157)$ & $\operatorname{ME}(n=176)$ & HE $(n=305)$ & $P$ value \\
\hline Mean age (y) & $64.2 \pm 11.7$ & $64.1 \pm 10.5$ & $64.6 \pm 11.5$ & .851 \\
\hline Male gender & $86(54.8 \%)$ & $83(47.2 \%)$ & $117(38.4 \%)$ & $.003^{*}$ \\
\hline Nonwhite race & $33(21.0 \%)$ & $26(14.8 \%)$ & $34(11.1 \%)$ & $.017 \dagger$ \\
\hline Smoking status & & & & .436 \\
\hline Never & $14(8.9 \%)$ & $24(13.8 \%)$ & $43(14.1 \%)$ & \\
\hline Past & $81(51.6 \%)$ & $90(51.1 \%)$ & $162(53.1 \%)$ & \\
\hline Current & $62(39.5 \%)$ & $62(35.2 \%)$ & $100(32.8 \%)$ & \\
\hline Prior stroke & $8(5.1 \%)$ & $7(4.0 \%)$ & $17(5.6 \%)$ & .741 \\
\hline Coronary artery disease & $36(22.9 \%)$ & $28(15.9 \%)$ & $54(17.7 \%)$ & .228 \\
\hline Hypertension & $89(56.7 \%)$ & $101(57.4 \%)$ & $162(53.1 \%)$ & .601 \\
\hline Congestive heart failure & $2(1.3 \%)$ & $1(0.6 \%)$ & $8(2.6 \%)$ & .220 \\
\hline Peripheral vascular disease & $7(4.5 \%)$ & $6(3.4 \%)$ & $11(3.6 \%)$ & .864 \\
\hline Deep vein thrombosis & $5(3.2 \%)$ & $6(3.4 \%)$ & $12(3.9 \%)$ & .907 \\
\hline Baseline FEV1\% predicted & $82.0 \pm 20.0$ & $82.6 \pm 19.3$ & $82.6 \pm 21.1$ & .951 \\
\hline Baseline DLCO $\%$ predicted & $73.0 \pm 20.9$ & $74.4 \pm 20.9$ & $73.2 \pm 21.6$ & .802 \\
\hline Body mass index & $27.0 \pm 5.6$ & $27.6 \pm 5.9$ & $27.1 \pm 6.6$ & .622 \\
\hline Prior cancer & $60(38.3 \%)$ & $55(31.3 \%)$ & $99(32.5 \%)$ & .347 \\
\hline Clinical stage & & & & .491 \\
\hline I & $139(88.5 \%)$ & $160(90.9 \%)$ & $283(92.8 \%)$ & \\
\hline II & $8(5.1 \%)$ & $6(3.4 \%)$ & $12(3.9 \%)$ & \\
\hline III & $10(6.4 \%)$ & $10(5.7 \%)$ & $10(3.3 \%)$ & \\
\hline
\end{tabular}

$P=.17$; LE versus HE, $P=.001 ;$ ME versus HE, $P=.06$. $\dagger$ LE versus ME, $P=.14$; LE versus HE, $P=.004$; ME versus HE, $P=.25$. 